
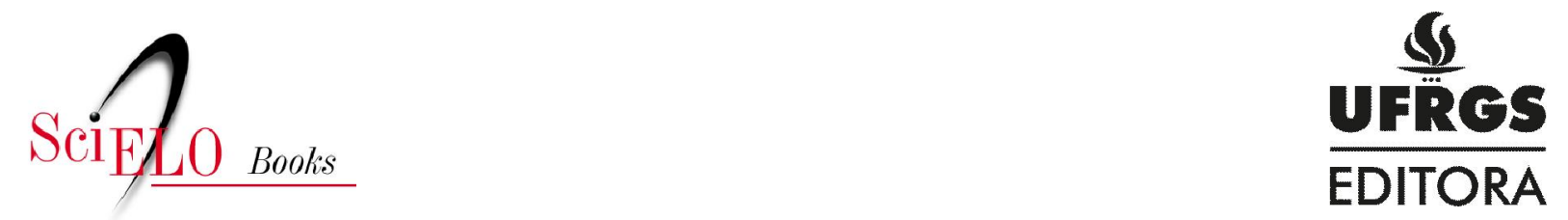

\title{
O que podemos explicar estudando carreiras políticas?
}

\author{
André Marenco
}

\section{SciELO Books / SciELO Livros / SciELO Libros}

MARENCO, A., org. O que podemos explicar estudando carreiras políticas? In: Os eleitos: representação e carreiras políticas em democracias [online]. Porto Alegre: Editora da UFRGS, 2013, pp. 31-51. ISBN 978-85-386-0384-9. Available from doi: $10.7476 / 9788538603849$. Also available in ePUB from: http://books.scielo.org/id/bfwrk/epub/marenco-9788538603849.epub.

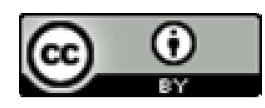

All the contents of this work, except where otherwise noted, is licensed under a Creative Commons Attribution 4.0 International license.

Todo o conteúdo deste trabalho, exceto quando houver ressalva, é publicado sob a licença Creative Commons Atribição $\underline{4.0}$.

Todo el contenido de esta obra, excepto donde se indique lo contrario, está bajo licencia de la licencia $\underline{\text { Creative Commons }}$ $\underline{\text { Reconocimento } 4.0 .}$. 


\section{O que podemos explicar estudando carreiras políticas?}

André Marenco*

Por que estudar elites políticas? O que se pode conhecer sobre formação, continuidade e mudança em instituições políticas a partir da investigação de padrões de recrutamento para postos públicos? Em que medida as condições de ingresso e mobilidade no interior de carreiras políticas podem ajudar a explicar a composição e durabilidade de organizações partidárias? Graus diferentes de profissionalização das lideranças políticas afetam processos de decisão sobre políticas públicas? Elites políticas importam realmente?

Há uma longa linhagem de estudos sobre elites políticas. A geração dos founding fathers de uma reflexão sobre elites políticas e sociais, dedicou-se a demonstrar como democracias continuariam a ser governadas por minorias dirigentes, embora pudessem variar quanto a recursos e a fórmula política (Mosca), graus de circulação inter ou intraelites (Pareto) e a importância de fatores organizacionais (Michels). Uma segunda geração de estudos sobre elites políticas dividiu-se em torno a controvérsia sobre o caráter monista ou pluralista de elites democráticas, enfatizando sua coesão ou, alternativamente, sua dispersão e heterogeneidade.

Desdobramento deste debate pode ser localizado no aporte oferecido pela sociologia política ao estudo de elites, em particular a partir da influência exercida pelos trabalhos de Pierre Bourdieu. Seu ponto de partida consistiu na indagação sobre a convivência entre uma tradição igualitária e republicana, derivada do iluminismo e da Grande Revolução, com a manutenção de assimetrias sociais e políticas. A resposta for-

"Professor Associado da Universidade Federal do Rio Grande do Sul, pesquisador do CNPq , integra o Grupo de Pesquisa/CNPq Instituições Políticas Comparadas/ iPoC. 
mulada pela escola francesa de sociologia política foi alicerçada em torno aos conceitos de homologia estrutural e reconversão.

Partindo da identificação de uma congruência entre posições sociais e valores, Bourdieu indicou que estruturas sociais seriam conformadas por uma homologia estrutural entre a hierarquia de posições fixadas nos campos econômico e cultural e as posições conquistadas no campo do poder (Bourdieu, 1989:188). Disto decorreria que o acesso à elite política, mesmo em instituições democráticas, não dependeria do caráter aberto destas elites, como supunha Mosca, sendo determinado por uma distribuição cumulativa de recursos de poder. Assim, a origem social maximizaria o acesso a recursos econômicos e a um capital escolar, ampliando probabilidades de monopolizar postos de poder, projetando, por fim, uma correspondência entre hierarquias sociais, baseadas em assets econômicos e culturais, e estruturas políticas. Da mesma forma, cargos superiores nas instituições políticas seriam ocupados por quadros recrutados nos estratos superiores na distribuição de recursos econômicos (Bourdieu, 1989; Gaxie, 1980).

O forte apelo oferecido pelo exame da posição social de políticos profissionais como procedimento confirmatório à natureza plutocrática das instituições políticas, mesmo democráticas, terminou por produzir uma espécie de uso by default deste modelo, com escassas indagações acerca de seu poder explicativo efetivo: on peut même parler ici d'une véritable 'routine scientifique', dans la mesure où les présupposés théoriques et méthodologiques qu'implique ce type de démarche ne sont la plupart du temps guère interrogés par ses utilisateurs (Sawicki, 1999:136). Nesta perspectiva, não parece tarefa difícil localizar estudos monográficos revelando elevada origem social e cultural de grupos de elites políticas em contextos nacionais ou subnacionais. A pergunta que se impõe a esta altura consiste em se elites são homogeneamente conformadas por homologia estrutural, e se, portanto, não variam de modo significativo em sua composição, origem social, processos de recrutamento e trajetórias institucionais, se, enfim, "elites políticas" são semelhantes, em que medida constituem uma categoria explicativa relevante para analisar diferenças em padrões de competição partidária e eleitoral, modelos institucionais poliárquicos, variações nos níveis de gasto público, implementação de políticas sociais ou escolhas macroeconômicas.

A agenda de investigação sobre elites políticas conheceu um beco sem saída quando terminou por focar sua atenção exclusivamente na hipótese 
que minorias governam, mesmo em democracias, e que minorias governantes são homogêneamente selecionadas. Se elites são quase sempre as mesmas, parece não haver relevância em estudá-las para compreender as variações institucionais observadas nas poliarquias contemporâneas.

Não são menores os impasses que podem ser identificados na agenda de estudos neoinstitucionalista, que propôs-se a isolar os constrangimentos produzidos por estruturas institucionais sobre a ação individual e escolhas públicas. Enquanto a apresentação de casos exemplares dos efeitos políticos provocados pelas regras institucionais na resolução de puzzles como o teorema da impossibilidade de Arrows, a tragédia dos comuns de Hardim, ou os problemas de coordenação da ação coletiva em Olson, tornou-se abundante na agenda da ciência política nas últimas duas décadas (March e Olsen, 1983; Evans, Rueschmeyer e Skocpol, 1985; Schepsle, 1995), mais escassos foram os avanços na direção de explicações sobre a origem e formação de instituições que - uma vez postas em marcha - supõe-se condicionem as interações sociais e os resultados dos conflitos políticos (Diermeier e Krehbiel, 2003).

Conforme advertência de Popper (1963), o desafio principal das Ciências Sociais consiste em identificar as consequências sociais não previstas, geradas a partir de ações humanas intencionais. A relação não-linear entre ações individuais orientadas por determinado fim e suas consequências ou engenharia institucional projetada para produzir resultados desejados e os resultados efetivos, é produto de efeitos perversos (Boudon, 1977) que resultam da interação de agentes estratégicos sob condições de informação assimétrica e incompleta. Isto explica porque a mesma configuração institucional aplicada a contextos e agentes distintos, produz resultados discrepantes.

Assim, o acento posto na influência das instituições sobre escolhas e ação individuais não deve subsumir a percepção de que instituições estáveis e duradouras são produto de ações e estratégias desenroladas previamente por indivíduos que permitiram a fixação da estrutura institucional que os constrange posteriormente. Isto significa que a gênese e morfologia das instituições políticas devem ser compreendidas de modo mais sensível ao reconstituir-se estratégias, trajetórias e background dos indivíduos que as dirigem, para compreender as condições da escolha institucional.

O que produz lealdade de indivíduos à instituições? Escolhas subotimas, nos sugere convincentemente proposições derivadas da rational 
choice theory. O problema consiste em que trata-se de uma resposta apenas descritiva. Por óbvio, a pergunta seguinte não pode deixar de ser: sob que configuração, instituições correspondem a um modelo de equilíbrio de Nash, ou seja, aquela na qual nenhum agente possui incentivos para alterar sua estratégia unilateralmente em busca de maximização de seus ganhos, através da deserção, adotando exit (Hirschman, 1977) ou projeto institucional (Tsebelis, 1998) como curso de ação? Provavelmente, instituições adquirem estabilidade sob condições de funcionamento centrípeto, no qual o núcleo dirigente controla a distribuição dos recursos estratégicos que constituem a vida organizacional, impondo integração vertical e lealdade interna.

Seguindo Hirschman (1970: 93), pode-se perguntar sob que condições estratégias orientadas para lealdade institucional se sobrepõe à escolhas nas quais a defecção constitui a melhor alternativa. Sua resposta sugere que instituições dotadas de vínculos de lealdade interna mais fortes são aquelas dotadas de procedimentos que fixam alto preço de entrada e mecanismos de iniciação severa para seus membros ou aspirantes: los honorários elevados para ingresar a um organismo y las penas severas por la salida son algunos de los instrumentos principales generadores o reforzadores de la lealtad que finalmente reprimen la salida, la voz o ambas cosas [...] cuando el ingreso a um organismo es caro o requiere una iniciación severa, se demorará al reconocimiento de todo deterioro por parte de los miembros, al igual que La iniciación de la voz. Padrões de seleção de ingresso e mobilidade em carreiras políticas podem ser vistos, nesta perspectiva, como um elemento para conformar as oportunidades de consolidação de instituições e sua influência sobre estratégias individuais.

A natureza das relações entre líderes e aderentes partidários e os mecanismos de lealdade produzidos em seu interior, fornecem, conforme Panebianco, a chave para desvendar a configuração de instituições como partidos políticos. Um quadro de estabilidade organizativa resulta, nesta perspectiva, do êxito de seus dirigentes em controlar recursos próprios de remuneração política. Podem apresentar-se como incentivos coletivos - a identidade compartilhada - ou seletivos, estes, presentes no status pela posição ou responsabilidade assumidos, ou em recompensas materiais. Nos velhos partidos de massa, a capacidade da organização preencher a vida social de seus membros - que a precariedade material e espiritual de sua existência privada muitas vezes não lhes permite - constitui, ainda, uma forma de remuneração que cimenta lealdades: oferecendo alterna- 
tivas de lazer, círculos de amizade, solidariedade, assistência e, inclusive, uma espécie de micromercado matrimonial, o partido converte-se em uma community of fate, que dissolve fronteiras entre indivíduo e coletivo. A importância destas formas diversificadas de aderência, capazes de integrar toda a heterogeneidade de seus membros pode ser melhor percebida quando se constata a relação entre o declínio do ativismo partidário e o encolhimento de estruturas capilares de arregimentação

Oportunidade para maior coesão partidária estaria associada ainda a seu padrão fundacional. Quando a organização expande-se por penetração, à partir de, e espelhando-se em seu núcleo partidário original, seriam maiores as probabilidades para a afirmação de identidades ao centro. Inversamente, crescendo por difusão, através da integração de elites locais/regionais em uma estrutura federativa, a organização estaria mais propensa à flexibilidade e a necessidade de negociações para a geração de consensos mínimos, tal como observado entre os partidos americanos. Interfere, igualmente, a natureza interna ou externa (Igreja, sindicatos, Estado) das fontes que emprestam sua legitimidade à organização, afetando as chances de domínio do núcleo dirigente e o tipo de relações que estabelece com seus seguidores.

A natureza predominante dos incentivos (coletivos/seletivos) e o controle sobre sua distribuição (concentrado/disperso) delineariam os contornos de cada organização partidária. Coesão e homogeneidade organizativas seriam conformadas pelas relações entre líderes e agrupamentos intrapartidários e a capacidade dos dirigentes em administrar áreas de incerteza, pontos críticos que, ao serem controlados, fornecem os meios para a construção de identidades partidárias consistentes: atributos coletivamente valorizados, reconhecidos nos quadros dirigentes; relações com a periferia partidária; controle sobre o fluxo de informações internas; e, mecanismos de recrutamento e seleção de candidatos a postos políticos. Como ilustração, pode-se considerar a observação de Tsebelis identificando no poder de veto dos órgãos dirigentes centrais, o traço distintivo dos partidos ingleses, com relação aos EUA: semelhante alteração (a supressão deste poder de veto) teria significado a americanização do Partido Trabalhista, no sentido de que deixaria de existir uma autoridade central no partido. O GMC de cada distrito estaria apto a indicar os candidatos de sua escolha sem enfrentar qualquer obstáculo e, a longo prazo, o grupo parlamentar compor-se-ia de MPs sem quaisquer vínculos comuns, mas que refletiriam fielmente o GMC de seus distritos . 
A estabilidade e consistência das organizações partidárias estão, assim, associadas à sua capacidade em assegurar uma condição de oligopólio sobre a oferta da representação política. O fornecimento de identidades não recambiáveis, para eleitores, e oportunidades de acesso a postos, para aspirantes à carreiras políticas constituem os assets que permitem à sua liderança a imposição de lealdades e relações hierárquicas.

Padrões de carreira oferecem um indicador acerca do controle exercido pela liderança partidária sobre seus seguidores. Carreiras políticas são impulsionadas por uma disponibilidade desigual de recursos eleitorais, como apoio e nominação partidária, acesso a patronagem e pork-barrel, fontes de financiamento, redes de lealdades e votos, e ainda, pelas regras que definem a ocupação de postos públicos (Norris, 1997; Best e Cotta, 2000, Pennings e Hazan, 2001; Katz, 2001). Quando a estrutura partidária fornece os meios necessários para a arregimentação eleitoral o aspirante à carreira deve adaptar-se às regras e diretrizes fixadas pela organização. Neste caso, a indicação para uma candidatura segue um modelo centrípeto (Panebianco, 2005), premiando lealdades confirmadas após anos de engajamento partidário. Sob esta situação, carreiras configuram-se como cursus honorum (Gaxie, 1993), quando o ingresso ocorre nos níveis inferiores da hierarquia partidária, exigindo longo intervalo temporal até a possibilidade de conquista de uma cadeira legislativa. Em suma, iniciação institucional severa, seguido por continuidade e previsibilidade nas interações entre os agentes, constituindo forma de jogo iterativo, no qual a repetição contribui para a produção de commitment, seja por informação seletiva, seja pelos custos da violação dos ritos e regras consagrados. Preferências passam a ser endogenamente constituídas e a preservação institucional, converte-se, de estratégia em utilidade por si própria. Carreiras políticas adquirem, sob estas coordenadas, padrão de seleção endógena (Dogan, 1999; Mastropaolo, 1990), oferecendo oportunidades para profissionalização dos quadros políticos, caracterizada por perfis enquadrados em 4 características: (a) vocação e ingresso precoce na atividade política, (b) carreiras políticas longas e duráveis, (c) capital político gerado principalmente a partir das funções políticas exercidas e , (d) o domínio de uma expertise específica da função política.

Em contraste, padrões de recrutamento lateral tendem a valorizar atributos adquiridos fora das fronteiras organizacionais. Conforme Dogan, processos de osmose podem representar metáfora sugestiva a respeito: en politique, l'osmose obéit aux mêmes lois que dans la nature: la diffusion se 
fait à travers de ses membranes perméables, entre positions adjacentes (Dogan, 1999, p. 173). Prestígio, posses e relações firmadas na vida privada são, meios eficazes para a obtenção de recursos estratégicos. Detendo recursos próprios, aspirantes a uma carreira política não dependem do aval institucional, podendo ignorá-la com menor risco para o ingresso ou continuidade em sua carreira. Inversamente, muitas vezes são os dirigentes institucionais que necessitam da notoriedade emprestada por seus nomes. Carreiras políticas são, com isto, mais rápidas e descontínuas, oferecendo oportunidade para aspirantes com escassa ou pequena experiência política.

$\mathrm{O}$ argumento adotado aqui consiste em que composição, recrutamento e circulação no interior de elites políticas afetam como e a medida em que grupos ou facções controlam recursos estratégicos e os convertem em coerção sobre o comportamento individual. Padrões de recrutamento endógenos, caracterizados por iniciação severa e longas trajetórias geram lealdades institucionais, terminando por configurar modelos path-dependent: ingresso seletivo e carreiras verticais induzem homogeneidade interna, maior economia na produção de informação, menores custos de transação e incerteza. Desta forma, oferecem insights para compreender-se como instituições tornam-se instituições.

Evidências de organizações partidárias estáveis podem ser detectadas quando estas convertem-se em parâmetro para o comportamento de seus membros e eleitores. Estabilidade na distribuição de votos eleitorais, disciplina nas decisões legislativas e controle sobre os procedimentos de seleção de carreiras políticas são indicadores de que organizações partidárias foram capazes de institucionalizar-se e estabelecer oligopólio sobre a oferta de representação política (Mair, 1997). As múltiplas dimensões que envolvem processos de institucionalização partidária tem sido consideradas em investigações sobre os partidos políticos na América Latina, com ênfase para os estudos sobre desempenho partidário em gabinetes presidencialistas e na tomada de decisões legislativas (Nohlen e Baeza, 1998; Figueiredo e Limongi, 1999; Lanzaro, 2001; Mainwaring e Shugart, 2002; Morgenstern e Nacif, 2002), estabilidade da arena eleitoral e a consistência dos vínculos sociais e ideológicos entre eleitores e partidos (Mainwaring e Torcal, 2005), ou incentivos à geração de reputação partidária ou personalizada produzidos pelas regras eleitorais (Carey e Shugart, 1996; Crisp et al., 2004). Menos frequentes tem sido investigações sobre estruturas organizativas dos partidos latino-americanos dirigidas para a reconstituição de processos decisórios internos, relações entre lideranças e membros e 
os padrões de recrutamento legislativo e seleção de carreiras políticas (Alcántara e Freidenberg, 2001; Jones, 2002; Jones et al., 2002; Freidenberg, 2003; Siavelis e Morgenstern, 2003). Investigar padrões de recrutamento legislativo, permite mensurar o grau em que organizações partidárias controlam oportunidades de ingresso e circulação em carreiras políticas, contribuindo para explicar diferenças verificadas em processos de institucionalização partidária (Panebianco, 2005). Nesta perspectiva, iniciação severa e recrutamento endógeno, quando o núcleo dirigente controla a distribuição dos recursos estratégicos para a seleção de carreiras políticas, impondo integração vertical e lealdade interna são fatores que envolvem efeitos do tipo positive feedback (Pierson, 2004), contribuindo para reforçar a estabilidade de estruturas partidárias.

Modelos explicativos

para padrões de carreiras políticas

Problema, na sequência, consiste em encontrar interpretações adequadas para explicar a variação nos modelos de carreira observados (endógenas/laterais). Se carreiras oferecem evidências acerca das condições mais ou menos favoráveis à profissionalização da atividade política, resta, ainda, explicar que condições favorecem estratégias de ingresso/mobilidade em cargos públicos baseados seja em recursos partidários ou, inversamente, pessoais, como suporte para trajetórias políticas.

Argumento de forte audiência na América Latina, como explicação para a manutenção da importância de carreiras laterais e recursos eleitorais personalizados na competição por cadeiras legislativas, enfatiza os efeitos produzidos por regras eleitorais baseadas em diferentes procedimentos de ordenamento de listas partidárias, seja reservando aos partidos o monopólio do rankeamento eleitoral, ou transferindo aos eleitores a chance de interferir sobre a composição final das nominatas partidárias legislativas. Nesta perspectiva, regras eleitorais de competição intrapartidária por votos preferenciais representariam um incentivo para a disputa por sufrágios personalizados, e o reforço do diferencial exercido pela posse de recursos individuais para o ingresso e mobilidade na carreira política. Não prevendo a possibilidade de as lideranças partidárias determinar uma hierarquia prévia dos candidatos, este procedimento reduziria os custos eleitorais para a violação de identidades partidárias, uma vez que, de acordo com esta perspectiva, sua eleição dependeria da quan- 
tidade de sufrágios personalizados conquistados, principal condição para definir o ordenamento dos candidatos. Desta forma, ao incentivar a competição intrapartidária, mecanismos de voto preferencial seriam responsáveis por provocar infidelidade, migração interpartidos, menor disciplina legislativa, votos personalizados, reproduzindo uma situação endêmica de fragilidade partidária (Carey e Shugart, 1996; Mainwaring, 1999; Ames, 2003; Norris, 2002; Norris, 2004; Crisp et al., 2004). Quadro comparativo mensurando os incentivos institucionais promovidos por diferentes modelos de listas eleitorais na a geração de reputação partidária ou pessoal como recurso para carreiras políticas, foi elaborado por Carey e Shugart (1996), criando um escore para medir os meios de controle à disposição da liderança partidária: prerrogativa das nominações e ordenamento dos eleitos (ballot), transferência de votos (pool), restrições à competição intrapartidária e a existência de barreiras à formação de novos partidos, promovida pela magnitude dos distritos eleitorais. Nesta direção, lista aberta, candidatos natos, e elevada magnitude das circunscrições eleitorais incrementariam o potencial de competição intrapartidária, reduzindo, paralelamente, o controle da liderança partidária sobre seus membros e candidatos e ampliando o valor de reputações pessoais como capital político. Ainda nesta perspectiva, fórmulas majoritárias uninominais, com nominação partidária, e, RP com lista fechada seriam exemplos de instituições que ao conferir maior estoque de recursos à disposição das lideranças partidárias, gerariam menor incentivo à manutenção de reputações partidárias. Nesta mesma direção, mas em outro trabalho, Carey (2002), sugere que as circunscrições binominais chilenas (two-member districts), ao induzir negociações intracoalizões sobre a distribuição das candidaduras, terminaria por incrementar a coesão de partidos e coalizões.

Analisando seis casos nacionais na América Latina, Crisp et al. (2004) isolaram duas variáveis como recursos explicativos para a geração de padrões de electoral connection: procedimentos partidários de seleção de candidaturas, de indicações centralizadas como no Chile, Costa Rica e Honduras, até descentralizadas, como na Colômbia, passando pelos casos intermediários da Argentina e Venezuela; paralelo, regras eleitorais de lista fechada ou com competição intrapartidária (compreendendo lista aberta e listas subpartidárias). Assim, decisões descentralizadas, combinado a competição intrapartidária constituiriam o contexto mais favorável à disputa por votos personalizados e políticas particularísticas. 
Em síntese, o argumento standard produzido pela literatura institucional sugere que sob regras que incentivam a competição intrapartidária - nas quais a ordem dos candidatos a ocupar as vagas geradas pela cota proporcional de cada partido, é definida pela votação preferencial de candidatos ou facções - as consequências serão estratégias de carreira política baseadas na reputação pessoal, viabilizadas preferencialmente por políticas distributivistas de alocação concentrada de recursos públicos (verbas, empregos) na constituency a ser conservada como condição para a manutenção e/ou mobilidade na carreira política. A comprovação de uma associação entre voto preferencial e precário controle partidário sobre o recrutamento legislativo deveria ser encontrada por evidências que revelassem padrões homogêneos segundo diferentes intervalos de tempo, distritos eleitorais e partidos políticos, dentro de cada procedimento eleitoral: listas fechadas/carreiras partidárias, voto preferencial/ recrutamento lateral.

As evidências, no entanto, parecem não confirmar esta suposição. Analisando o controle partidário sobre seleção de carreiras legislativas no Brasil - medido pelo tempo de filiação partidária prévio à conquista da cadeira parlamentar e pela migração, mudança de partido durante a legislatura - pode-se verificar que a adoção de estratégias de infidelidade não constitui fenômeno homogêneo, variando segundo: (1) ciclos políticos, marginal entre 1945/64 e crescente entre 1986/2002 (Marenco dos Santos, 1997; 2001); (2) partidos políticos, mais frequente em partidos conservadores, e residual em legendas de esquerda (Marenco dos Santos, 2003; 2004; 2005); (3) características contextuais de cada circunscrição eleitoral (que correspondem no Brasil, aos estados), positivamente relacionada com as taxas estaduais de volatilidade eleitoral, sendo irrelevante o efeito provocado pela magnitude eleitoral, contrariando a indicação de Carey e Shugart sobre o efeito positivo de M na fragilidade partidária (Marenco dos Santos, 2006); (4) Experiência partidária, medida pelo tempo de filiação partidária prévio à conquista da cadeira legislativa (Marenco dos Santos, 2006; Marenco dos Santos e Serna, 2007). Neste sentido, carreiras baseadas em maior probabilidade de defecção partidária podem ser verificada entre deputados filiados a intervalos temporais curtos no partido responsável pela vaga e, quando a troca de partido é seguida pela tentativa de reeleição para a legislatura seguinte, observa-se menores taxas de reeleição entre os infiéis, e pior desempenho eleitoral (medido por votos nominais e posição na ordem final) entre aqueles que trocaram de legenda após períodos de filiação partidária prévia mais longos. 
Interpretação alternativa e talvez mais apta para explicar variações nos padrões de carreiras políticas observadas entre partidos competindo no interior das mesmas regras eleitorais, pode ser encontrada em modelos que enfatizam a configuração organizacional de cada partido e os processos de seleção de candidaturas promovidos em seu interior. Nesta direção, Rahat e Hazan (2001) constroem um modelo analítico para mensurar o controle partidário no recrutamento parlamentar, classificando os procedimentos segundo quatro dimensões deste processo: (1) a composição do selectorado, em um eixo inclusão/exclusão, conforme a seleção dos candidatos partidários é promovida em primárias abertas a todos os eleitores, em primárias restritas aos filiados partidários, em fóruns partidários eletivos, por órgãos não eletivos ou, no extremo, por decisão de lideranças, como no caso de partidos ortodoxos em Israel, quando a definição de candidaturas é exercida por rabinos; (2) quem pode ser candidato: da oportunidade mais inclusiva, quando qualquer cidadão pode candidatar-se, passando por circunstâncias em que a apresentação de candidatura é restrita a membros partidários ou, no extremo, quando são previstos requisitos adicionais, como no caso do Partido Socialista belga, onde a apresentação de candidatura exige filiação partidária superior a 5 anos, comprovação de consumo na cooperativa do partido, frequência dos filhos a escolas estatais e ativismo de esposas e filhos em organizações de mulheres e juventude do partido; (3) graus de descentralização territorial (nacional/regional/local) e funcional (nacional/grupos/subgrupos) na indicação de candidaturas e, (4) o procedimento decisório para a nominação de candidatos, indo da votação formal sem alteração posterior, indicação de listas por dirigentes com ratificação posterior, ou o simples nominação appointment das listas pelos dirigentes partidários. Maior concentração decisória (filtros para apresentação de candidaturas), selectorate restrito, centralização territorial e/ou funcional e appointment deveria corresponder a maior controle e padrões de carreiras dominantemente partidárias. Na mesma direção, para Bowler (1999) quanto maior a inclusão de um selectorado externo, menores seriam as oportunidades para coesão partidária, uma vez que carreiras dependeriam de agentes e recursos laterais em relação às estruturas organizacionais dos partidos.

Nesta direção, Siavelis e Morgenstern (2003) sugerem uma associação entre procedimentos centralizados de seleção de candidatos - com regras estritas e coercitivas, controle partidário sobre fundos públicos de campanhas, candidaturas natas de incumbents e quotas, quando existen- 
tes, ordenadas pelas lideranças - e incentivos para a promoção de party loyalists identificados por longas carreiras internas à organização partidária. Os efeitos provocados por indicação centralizada seriam ainda mais fortes, quando combinados à elevada magnitude das circunscrições eleitorais, fator que reforçaria (contrariando a hipótese de Carey e Shugart) reputações partidárias.

Uma aplicação deste modelo organizacional pode ser encontrado em trabalho de Navia (2004) sobre diferenças interpartidárias nos padrões chilenos de recrutamento parlamentar. Seus achados identificam UDI e PPD como os partidos com processos mais centralizados de seleção de candidaturas, enquanto o PDC apresentaria maior democracia interna e menores graus de controle exercido pelos dirigentes sobre a escolha de candidatos. O paradoxal, neste caso, consiste em que a centralização decisória de PPD e UDI produz como resultado perfis menos partidários de carreira política, enquanto a maior descentralização das escolhas entre democrata-cristãos, gera candidatos cujas trajetórias políticas foram projetadas principalmente dentro das fronteiras partidárias (Marenco dos Santos e Serna, 2007). O que parece indicar, alternativamente, que o método da escolha de candidatos pode não oferecer uma previsão segura sobre os resultados, em termos de padrões endógenos e perfis partidários de recrutamento legislativo.

Seria preciso considerar, nesta perspectiva, os recursos políticos controlados pelos candidatos individuais e as condições que estes dispõe para impor seus nomes ao selectorate partidário, seja este formado por procedimentos centralizados ou descentralizados. Nesta direção, Katz e Mair (1994) sugerem que - contrariando a hipótese de Rahat e Hazan - um selectorado mais inclusivo pode representar reforço no poder e recursos de dirigentes centrais, em detrimento à lideranças intermediárias, criando incentivos para maior coesão e estratégias de carreiras políticas endógenas.

\section{Em busca de uma racionalidade contextual}

No início do século, Max Weber deslocou o foco de sua observação para o interior dos partidos, buscando captar mudanças no perfil dos indivíduos voltados à atividade política. A pista para explicar as metamorfoses na fisionomia partidaria estaria na supremacia conquistada por profissionais - funcionários, nas organizações europeias, o boss, na política americana - sobre notáveis, com o subsequente enquadramento dos 
parlamentares à disciplina partidária. Sugestiva a respeito é a descrição do cenário da Inglaterra até 1868: predominam honoratiores, como o pastor anglicano, professores e proprietários, entre os tories, o predicador e artesãos com oportunidade para firmar contatos sociais, nos whigs. Para todos então, a política representava uma ocupação acessória, espécie de título honorífico válido para confirmar um prestígio social. O incremento na competição leva ao aparecimento do election agent, que gradativamente amplia sua ascendência, empresariando votos e aliando-se à figuras como o demagogo plebiscitário, a exemplo de Gladstone, e, mais tarde, com o whip. Transformando-se de clube de notáveis em máquina profissional, partidos adquirem centralização e densidade organizativa.

Desvendar a natureza dos meios que dispõem os homens políticos permite entender os vínculos que constituem a relação de representação e as oportunidades oferecidas a uma carreira política aos portadores de certos recursos ou atributos socialmente valorizados. A trajetória dos homens políticos nas democracias contemporâneas revela a presença de diferentes padrões de capital político operando como forma de reconhecimento na qual se funda a confiança emprestada pelos constituintes.

De um lado, recursos pessoais, traduzidos na confiança e reconhecimento intrínsecos de um indivíduo, baseados em seu prestígio, distinção, reputação, títulos e qualificações socialmente valorizados. Não se confunde, como adverte Bourdieu com o carisma, tal como descrito por Weber. Este, é o resultado de uma ação inaugural, irrompida no vazio produzido por uma crise social e o silêncio institucional. Dispõe do magnetismo da figura excepcional, do profeta, herói ou líder messiânico, que condensa em sua imagem a multiplicidade de significados projetados por seus seguidores.

Diferente, o capital pessoal de notoriedade é forjado ao longo de uma vida inteira, na construção paciente de um nome, uma reputação. Pode dispensar a retórica, o apelo inflamado, retendo a intimidade que cimenta uma vasta teia de relações sociais. A ocupação profissional oferece uma oportunidade para o destaque individual. A disponibilidade ou flexibilidade do tempo permitidas em certas profissões liberais, o preparo cultural e o próprio afazer profissional que predispõe o indivíduo para uma carreira política e o eleitor, para reconhecê-lo como alguém preparado. É o caso do médico dedicado ou do advogado eloquente. A carreira política se oferece como oportunidade para evitar a depreciação de um patrimônio de reputação e reconhecimento, através do deslocamento en- 
tre campos distintos, e a reconversão do capital social em um trunfo mais rentável e legítimo.

Em outro extremo, o indivíduo não dispõe de atributos pessoais, tampouco dos recursos materiais indispensáveis para o début de uma carreira política bem sucedida. Seu aporte é oferecido por um capital coletivo, resultado da investidura a ele conferida por seu partido, sindicato, círculo de interesses ou movimento. Suporte financeiro, apoio militante, emblemas e interpelações ideológicos compensam a carência de atrativos individuais, ao mesmo tempo que submetem seu beneficiário à organização capaz de provê-los. Candidatos de origem social mais baixa, que não dispõe de recursos eleitorais próprios, precisam compensar esta carência com o aval e suporte partidário sob a forma de ajuda financeira, apoiadores voluntários, funcionários profissionais, estrutura logística e organizacional, obtidos em contrapartida à lealdade construída após longo tempo de party membership, induzindo processo de self-reinforcing para carreiras partidárias (Fiorina, 1997; Dogan, 1999; Best e Cotta, 2000; Katz, 2001). Desta forma, partidos de esquerda apresentariam maior diversificação social na composição de seus eleitos, bem como vínculos partidários mais duráveis e prévios ao início da carreira política. Em contraste, organizações partidárias tradicionais recrutam seus candidatos com capital eleitoral pessoal e carreiras construídas prévia e externamente à vínculos partidários estáveis. Por outro lado, o tempo de existência de diferentes organizações partidárias representa uma variável importante para a definição de modelos de carreiras políticas: organizações dotadas de longevidade temporal são capazes de impor trajetórias endógenas a seus candidatos (Serna, 2004; Marenco dos Santos, 2004 e 2005; Marenco dos Santos e Serna, 2007).

Mercados políticos censitários, até meados do século XIX, foram domínio de notáveis. Candidatos - da mesma forma que seus eleitores dispunham de fortuna pessoal, diploma, relações e reputação territorial. Neste momento, a distância social entre representante e representados é reduzida, constituindo transações virtualmente igualitárias, personalizadas, face a face. Distâncias ideológicas entre representantes são limitadas, não oferecendo fundamento para alinhamentos permanentes. Eleitores são menos sensíveis à afirmação ideológica de seu campo, ou a derrota do adversário - que, afinal, até este momento, não é tão diferente assim - do que com o retorno exclusivo que a confiança emprestada possa oferecer. Distinguido por seus pares para representar os interesses 
da circunscrição territorial, a margem de autonomia do parlamentar em relação a esta, é restrita.

O alargamento do sufrágio introduziu no mercado eleitoral um novo pessoal político, de origem social mais baixa, que não dispunha de prestígio individual, posses materiais e recursos de patronagem. Podiam ser egressos das classes médias como os quadros políticos do radicalismo, na França da Terceira República, ou do mundo sindical como na social-democracia alemã. Em comum, o fato de constituírem uma nova relação com a atividade política, agora não mais apenas ação honorífica, mas causa a alcançar e, fonte de sobrevivência material. Para enfrentar a concorrência de políticos tradicionais, precisam recorrer ao capital político emprestado pelo partido, permitindo ao aspirante compensar a carência de atributos pessoais - notoriedade, diploma, posses - pela oferta de contrapartidas simbólicas como programas, visões de mundo, valores éticos, bandeiras sociais, transferidos pela identificação partidária .

Tornando-se eficazes como interpelação eleitoral, rótulos como esquerda e direita, social-democracia, democracia-cristã, trabalhista, conservador, sublimam personalidades sociais, fornecendo novas identidades como senha para o ingresso no campo político. Transcendendo à confiança, conhecimento e lealdade pessoal, a natureza dos vínculos que ligam representantes e representados adquire contornos identitários, fundados na percepção do pertencimento a uma comunidade de valores ou interesses compartilhados. Plus les marchés politiques sont différenciés, lembra Gaxie, plus les transactions prennent le caractère d'un échange de croyances.

A seletividade nos padrões de carreira política pode ser mensurada agora no rigor em que a instituição investe (somente) aqueles que investiram na instituição. Ou seja, quando serviços prestados e a fidelidade ao partido são os filtros que condicionam oportunidades de ascensão na hierarquia da elite política. Após ter dedicado boa parte de sua vida às tarefas de organização do partido, o indivíduo resgata o tempo e a energia investidos, convertendo-os em suporte coletivo (militância, finanças) para sua campanha.

O oligopólio partidário sobre a produção da representação permite, assim, uma sedimentação da classe política, com menor renovação, carreiras parlamentares mais longas e vínculos partidários mais estáveis. A profissionalização da atividade política é o resultado de certa previsibilidade nas oportunidades para a carreira política, permitindo que o aspirante possa voltar-se precocemente, consagrando desde cedo sua vida aos afazeres públicos. 
A configuração peculiar das instituições públicas no ocidente, pode ser ilustrada pela figura do profissional da política, identificado, conforme Dogan, por seu perfil singular: vocação precoce para a política, longas carreiras, recursos extraídos principal ou exclusivamente das atividades políticas exercidas e o experiência adquirida na trajetória política, revelada na habilidade para compromissos e negociações, e no uso da palavra. Seu engajamento não ocorre de modo ocasional, como distinção honorífica ou na participação eventual no dia de eleição, em uma reunião pública ou na expressão de uma opinião. Em direção semelhante, Gaxie e Offerlé sugerem que o homem político se destaca pela carreira estável e o treinamento constituído ao longo da trajetória percorrida entre postos públicos e a organização partidária que permitem l'aquisition d'un savoir-faire organizationnel et à l'apprentissage de technologies indispensables à l'exercice du travail politique: prise de parole, rédaction de tracts, maîtrise de techniques de contrôle et de manipulation d'assemblées, accoutumance à la discussion avec des responsables administratifs ou politiques... et a enraciné un sentiment de competénce politique. Descartando-se da vida social, o exercício da atividade política adota práticas especializadas que se diferenciam dos mecanismos que regem outras esferas sociais, como o domínio de textos sagrados, no campo religioso, o conhecimento técnico, entre a administração pública ou privada, o título de propriedade, no mercado.

O tempo oferecido por longas carreiras vivenciadas em comum, o sentimento de um destino compartilhado imposto pela própria natureza negocial da representação nos Legislativos, o treinamento institucional, contribuem para a produção de um estoque de informação compartilhada e a criação de normas que regem as interações entre profissionais e conferem autoridade e prestígio em decorrência da obediência a elas. Um bom exemplo é o mecanismo de seniority, que regula a ocupação de postos na House of Representatives americana. Premiando a continuidade na carreira, esta regra termina por valorizar parlamentares que ao longo do tempo tenham incorporado as normas da casa. Orientando-se pela deferência a procedimentos aceitos entre os pares e confirmados pela Instituição, o representante amplia suas oportunidades de carreira, uma vez que as chances da reeleição e da própria sequência da carreira estão condicionadas por sua habilidade para negociar projetos e demandas de interesse de seus eleitores. Experiência política converte-se, assim, em um recurso valorizado como meio para a projeção de uma carreira pública. 
A supremacia das organizações partidárias na configuração do recrutamento parlamentar e a afirmação do homem de partido sobre o notável, constatadas por Michels e Weber no início do século, não constituíram a última palavra na configuração das oportunidades para carreiras políticas. Como o próprio Weber já intuia, os mercados eleitorais continuariam sendo generosos com os diversos tipos de oferta existentes no mundo político. Notáveis sobreviveram em nichos à disposição de indivíduos aptos a acionar redes de relações pessoais e contrapartidas exclusivas ao crédito emprestado pelo eleitor. Também o freshman, que ingressa nos postos mais elevados da carreira pública sem uma experiência política prévia, continuou desfiando, com êxitos localizados, aos políticos veteranos no ramo.

\section{Fecho}

Porque estudar carreiras políticas? Em que medida, rastrear condições de ingresso e mobilidade em cargos políticos pode ajudar na compreensão sobre instituições públicas? Para tentar responder à estas questões, o argumento desenvolvido neste texto desdobrou-se em duas direções: em primeiro lugar, seguindo a pista indicada por Hirschman, de que lealdade institucional está relacionada à processos que fixem elevados custos de entrada e iniciação severa, traduzidos em padrões endógenos de carreira política, caracterizados por ingresso precoce na atividade política, carreiras longas e estáveis, recursos políticos produzidos a partir das funções políticas exercidas e expertise política; na sequência, procurou-se isolar as condições que oferecem oportunidades para carreiras endógenas. Nesta direção, retomando senda fixada por estudos seminais de Weber e Michels sobre as mudanças provocadas pela expansão do sufrágio e profissionalização da atividade política, procurou-se acentuar que carreiras endógenas e profissionalizadas são mais prováveis sob condições de assimetria na alocação de recursos sociais e econômicos, quando indivíduos ao não dispor de dinheiro, status social e redes de relações pessoais, dependem dos recursos alocados por organizações partidárias (finanças, trabalho voluntário e rótulos ideológicos), submetendo-se como contrapartida, à regras internas destas organizações, fenômeno traduzido em longos intervalos de dedicação e militância partidária. Revelar diferenças nas bases sociais de recrutamento político abre ângulo promissor, assim, para explicar as condições de emergência de organizações partidárias fortemente institucionalizadas. 


\section{Referências}

ALCÁNTARA, M.; FREIDENBERG, F. Partidos políticos de América Latina. Salamanca, Ediciones Universidad de Salamanca, 2001.

AMES, B. Os entraves da democracia no Brasil. Rio de Janeiro, FGV, 2003.

BEST, H.; COTTA, M. Parliamentary Representatives in Europe 1848-2000. Oxford University Press, 2000.

BEST, H.; GAXIE, D. "Detours to modernity: long-term trends of parliamentary recruitment in Republican France 1848-1999”. In: BEST, Heinrich and COTTA, M. Parliamentary representatives in Europe 1848-2000. Legislative recruitment and careers in eleven european countries. London: Oxford University Press, 2000.

BOUDON, R. Rio de Janeiro, Zahar, 1997.

BOURDIEU, P. O Poder Simbólico. Lisboa, Bertrand, 1989.

BOWLER, S.; FARRELL, D.; KATZ, R. Party cohesion, party discipline and parliaments. In:__. Party discipline and parliamentary government. Ohio State University, $\overline{1999 .}$

BRIQUET, J-L. Limperatif du changement. Critique de la classe politique et renouvellement des parlementaires dans la crise italienne (1992-1994). In: OFFERLÉ, Michel. La profession politique. XIXe.-Xxe. Siècles. Paris, Belin, 1999. CAREY, J.; SHUGART, M. "Incentives to cultivate a personal vote: a rank ordering of electoral formulas". Electoral Studies, v. 13, n. 4, p. 417-439, 1996.

CAREY, J. Parties, coalitions and the Chilean Congress in the 1990s. In: MORGENSTERN, S.; NACIF, B. Legislative politics in Latin America. Cambridge University Press, 2002.

COLLOVALD, A. La République du militant. Recrutement et filières de la carriere politique des deputés socialistes: In: BIRNBAUN, P. (Ed.). Les Élites Socialistes au Pouvoir, 1981-1985. Paris, Presses Universitaires de France, 1985.

CRISP, B.; ESCOBAR-LEMMON, M.; JONES, B.; JONES, M.; TAYLOR-ROBINSON, M. "Vote-seeking incentives and legislative representation in six presidential democracies". The Journal of Politics, v. 66, n. 3, p. 823-846, 2004.

DIERMEIER, D.; KREHBIEL, K. Institutionalism as a methodology. Journal of Theoretical Politics, 15/2, 2003.

DOGAN, M. Les professions propices à la carrière politique. In: OFFERLÉ, M. La profession politique. XIXe.-Xxe. Siècles. Paris, Belin, 1999.

ERICKSON, L. In: NORRIS, P. Passages to power. Legislative recruitment in advanded democracies. Canada, Cambridge University Press, 1997.

EVANS, P; RUESCHEMEYER, D.; SKOCPOL, T. Bringing the State Back. In: New Perspectives on the State as Institution and Social Actor. Cambridge University Press, 1985. 
FIGUEIREDO, A.; LIMONGI, F. Executivo e Legislativo na nova ordem constitucional. São Paulo, FGV, 1999.

FIORINA, M. Professionalism, realigment and representation. American Political Science Review, 91/1, 156-162, 1997.

FREIDENBERG, F. Selección de candidatos y democracia interna en los partidos de América Latina. Lima, IDEA, 2003.

GAÏTI, B. 'Syndicat des anciens' contre 'forces vives' de la nation. Le renouvellement politique de 1958. In: OFFERLÉ, M. La profession politique. Paris, Belin, 1999.

GAXIE, D. La Démocratie Representative. Paris, Montchrestien, 1993.

. Economie des partis et rétributions du militantisme. Paris, Revue $\overline{\text { Française de Science Politique, 27/1, février, } 1977 .}$

. Les logiques du recrutement politique. Paris, Revue Française de Science Politique, 38/3, juin 1980.

GAXIE, D.; OFFERLÉ, M. Les militants syndicaux et associatifs au pouvoir. Capital collectif et carrière politique. In: BIRNBAUN, P. (ed.). Les Élites Socialistes au Pouvoir, 1981-1985. Paris, Presses Universitaires de France, 1985.

HIRSCHMAN, A. Salida, voz y lealtad. Mexico, Fondo de Cultura Económica, 1977.

IHL, O. 'Deep pockets'. Sur le recrutement ploutocratique du personnel politique. In: OFFERLÉ, M. La profession politique. Paris, Belin, 1999.

JONES, M. et al. Amateurs legislators-professional politicians. The consequences of party-centered electoral rules in a Feeral system. American Political Science Review, 46:3, p. 456-469, 2002.

JONES, M. Back Rooms or Ballot Boxes?: Candidate Nomination in Argentina, Comparative Political Studies, 35:4, p. 413-36, 2002.

. "Explaining the high level of party discipline in the argentine congres". In: MORGENSTERN, S.; NACIF, B. (Eds.). Legislative politics in latinoamerica. Cambridge University Press, 2002.

JOUVENEL, R. La république des camarades. Paris, Grasset, 1924.

KATZ, R.; MAIR, K. How parties organize: change and adaptation in party organizations in Western democracies. London, Sage, 1994.

KATZ, R. S. "The Problem of Candidate Selection and Models of Party Democracy". Party Politics 7: 277-296, 2001.

KIEWIET, D. R.; ZENG, L. An analysis of congressional career decisions, 19471986. American Political Science Review, 87/4, 1993.

KNAPP, A. Vers un government d'inconnus? hommes politiques et hauts functionaires en Grande-Bretagne. In: SULEIMAN, E.; MÉDRAS, H. Le Recrutement des Élites en Europe. Paris, La Découverte, 1995.

LANZARO, J. (comp.). Tipos de presidencialismo y coaliciones políticas en América Latina. Buenos Aires: CLACSO, 2001. 
MAINWARING, S. Rethinking party systems in the third wave of democratization. The case of Brazil. Stanford: Stanford University Press, 1999.

MAINWARING, S.; SHUGART, M. (compiladores). Presidencialismo y Democracia en América Latina. Buenos Aires, Paidós, 2002.

MAINWARING, S.; TORCAL, M. Party institutionalization and party system theory after the third wave of democratization. Kellog Institute Working Papers Series WPS\#319. University of Notre Dame, Notre Dame, Indiana: The Helen Kellogg Institute for International Studies, 2005.

MAIR, P. Party system change: approaches and interpretations. Oxford University Press, 1997.

MARCH, J.; OLSEN, J. Redescovering institutions. The organizational basis of politics. New York, Free Press, 1989.

MARENCO DOS SANTOS, A. Nas fronteiras do campo político: raposas e ousiders no Congresso Nacional. Revista Brasileira de Ciências Sociais. São Paulo, v. 33, p. 87-101, 1997.

. Sedimentação de Lealdades Partidárias no Brasil: Tendências e Descompassos. Revista Brasileira de Ciências Sociais. São Paulo, v. 16, n. 45, p. 69-83, 2001.

. Partidos em carne e osso: votos e deputados nas eleições de 2002. Cadernos Adenauer. Rio de Janeiro, v. IV, n. 1, 2003.

. Le renouveau politique: carrières politiques et liens de parti au Brésil [1946-2002]. Politique et Societés. Montrèal, 23/2, 2004.

. Still a traditional political class? Patterns of parliamentary recruitment in Brazil. Canadian Journal of Latin American and Caribbean Studies, 30/60, 2005.

. Regras eleitorais, deputados e fidelidade partidária. In: SOARES, G. D.; RENNÓ, L. (Org.). Reforma Política. Lições da História Recente. Rio de Janeiro, Fundação Getúlio Vargas, 2006.

MARENCO DOS SANTOS, A.; SERNA, M. Por que carreiras políticas na esquerda e direita não são iguais? Recrutamento legislativo no Brasil, Chile e Uruguai. Revista Brasileira de Ciências Sociais. v. 64, p. 93-113, 2006.

MASTROPAOLO, A. Parlamenti e parlamentari neglianni ottanta. Rivista Italiana di Scienza Politica. XX,1, 1990.

MORGENSTERN, S.; NACIF, B. (Eds.). Legislative politics in Latin America. Cambridge University Press, 2002.

NAVIA, P. Legislative Candidate Selection in Chile. Working Paper for the symposium Pathways to Power: Political Recruitment and Democracy in Latin America, Graylyn International Conference Center Wake Forest University, Winston-Salem, NC, 2004. 
NOHLEN, D; BAEZA, M. F. (Eds.). El presidencialismo renovado. Instituciones y cambio politico en America Latina. Caracas, Nueva Sociedad, 1998.

NORRIS, P. Legislative Recruitment. In: LeDUC, L.; NIEMI, R. G.; NORRIS, P. Comparin Democracies. SAGE Publications, London, 1996.

. Passages to power. Legislative recruitment in advanced democracies. Cambridge University Press, 1997.

. Ballot Structures \& legislative behavior, Paper for the conference Exporting Congress on World Legislatures. Florida International University, 2002.

. Electoral engineering. Voting rules and political behavior. Cambridge University Press, 2004.

OFFERLÉ, M. La profession politique. XIXe.-XXe. Siècles. Paris, Belin, 1999.

PANEBIANCO, Â. Modelos de Partido. Organização e poder nos partidos politicos. São Paulo, Martins Fontes, 2005.

PENNINGS, P.; HAZAN, R. "Democratizing Candidate Selection: Causes and Consequences". Party Politics, 7, p. 267-275, 2001.

PIERSON, P. Politics in time. History, institutions and social analysis. Princeton University Press, 2004.

POLSBY, N. The Institutionalization of U.S. House of Representatives. American Political Science Review, LXII, march, 1968.

POPPER, K. Conjectures and Refutations: The Growth of Scientific Knowledge. Routledge, 1963.

RAHAT, G.; HAZAN, R. Candidate selection methods. An analitycal framework. Party Politics, 7/3, p. 297-322, 2001.

SAWICKI, F. Classer les hommes politiques. Les usages des indicateurs de position sociale pour la comprehension de la professionalization politique. In: OFFERLÉ, M. La profession politique. XIXe.-XXe. Siècles. Paris, Belin, 1999. SERNA, M. Reconversão democrática das esquerdas no Cone Sul: trajetórias e desafios na Argentina, Brasil e Uruguai. São Paulo, Edusc, 2004.

SHEPSLE, K. Studying institutions: some lessons from the rational choice approach. In: FARR, J.; DRYZEK, J.; LEONARD, S. Political Science in History. Research programs and political traditions. Cambridge University Press. 1995.

SIAVELIS, P.; MORGENSTERN, S. Political Recruitment and Candidate Selection in Latin America: a framework for analysis. Working Paper for the symposium Pathways to Power: Political Recruitment and Democracy in Latin America, Wake Forest University, Winston-Salem, NC, 2003.

TSEBELIS, G. Jogos ocultos: escolha racional no campo da política comparada. São Paulo, Edusp, 1998.

WEBER, M. Economia y sociedad. Mexico, Fondo de Cultura Económica, 1984. WESSELS, B. In: NORRIS, P. Passages to power. Legislative recruitment in advanded democracies. Cambridge University Press, Germany, 1997. 